\title{
COMPARISON OF EFFICACY OF LEVOBUPIVACAINE IN TRANSVERSE ABDOMINIS PLANE BLOCK FOR POSTOPERATIVE ANALGESIA IN PATIENTS UNDERGOING CAESAREAN SECTION: A DOUBLE BLINDED, RANDOMIZED STUDY
}

\begin{tabular}{ll} 
Dr Praveen S & Assistant Professor, Shimoga Institute of Medical Sciences, Shimoga. \\
\hline Dr Shashank M* & $\begin{array}{l}\text { Assistant Professor, Basaveshwara Medical College \& Hospital, } \\
\text { Chitradurga. }{ }^{*} \text { Corresponding Author }\end{array}$ \\
\hline
\end{tabular}

ABSTRACT Background: Dexamethasone has a long and efficient glucocorticoid structure and presents antiinflammatory properties. When used as an adjuvant to local anaesthetics, it prolongs the duration of analgesia. The aim of this study was to determine the effect of dexamethasone as an adjuvant to levobupivacaine in TAP block given to patients who underwent caesarean section.

Materials \& Methods: 70 patients posted for caesarean section under spinal anaesthesia were included in the study and divided into two groups. Group A received bilateral $30 \mathrm{ml} \mathrm{0.25 \%} \mathrm{levobupivacaine} \mathrm{and} 2 \mathrm{ml}$ dexamethasone(8mg). Group B received bilateral $30 \mathrm{ml} 0.25 \%$ levobupivacaine and $2 \mathrm{ml} 0.9 \% \mathrm{NaCl}$ in a TAP block performed with ultrasonography. The time needed for the first rescue analgesia in the postoperative period was recorded. $24 \mathrm{hr}$ tramadol consumption \& VAS was recorded.

Results: Time for first analgesic administration (tramadol) was prolonged significantly in Group $\mathrm{A}$ (mean $\pm \mathrm{SD}-12.24 \pm$ $1.22 \mathrm{hrs}$ ) as compared to Group B (mean $\pm \mathrm{SD}-8.37 \pm 1.07 \mathrm{hrs}$ ), P $<0.0001$. Tramadol requirement for $24 \mathrm{hrs}$ in Group A was $115.71 \pm 16.89 \mathrm{mg}$ and for Group B was $198.57 \pm 22.64 \mathrm{mg}$, which was statistically significant $(\mathrm{P}<0.0001)$. VAS was noted at 2, 4, $6,8,12,18$ and $24 \mathrm{~h}$. VAS was greatly reduced in group A for the first $8-10 \mathrm{~h}$ post-operatively as compared to patients in group B. Conclusions: Dexamethasone when used as an adjuvant to levobupivacaine in TAP block, enhances the duration of block \& decreases opioid consumption in the post- caesarean section patients.

KEYWORDS : levobupivacaine, dexamethasone, TAP block, postoperative analgesia.

\section{INTRODUCTION}

Pain is the most common \& most anticipated complaint during or after any surgery. Failure to tackle this will lead to various cardiovascular \& respiratory complications \& hence prolongs the hospital stay. After caesarean section mother-baby bonding, care of baby and breastfeeding can be affected greatly if there is inadequate post-operative pain relief. ${ }^{[1]}$ Immobility due to pain can increase the risk of thromboembolism, myocardial ischaemia \& arrythmias. ${ }^{[2]}$ The pain management should not only be adequate but also safe for the breastfeeding of the baby. ${ }^{[3]}$

Pain arising after abdominal surgeries have two components somatic (due to abdominal wall incision) and visceral (from the uterus) $)^{[3]}$. Variety of methods have been used to provide analgesia post caesarean section. Systemic or neuraxial opioids are widely used for treating postoperative pain, as they are counteractive against both the components but are associated with undesirable side effects. NSAIDS alone are inadequate to treat post-caesarean pain. Currently, multimodal analgesic technique involving abdominal nerve block with parenteral analgesics is providing excellent analgesia \& making postoperative stay more comfortable.

Transverse abdominis plane (TAP) block is a regional technique that blocks abdominal wall neural afferents between $\mathrm{T} 6$ and $\mathrm{Ll}$ and thus can relieve pain associated with an abdominal incision. ${ }^{[4,5]}$ TAP is a neurovascular plane located between the internal oblique and transverse abdominis muscles and nerves supplying abdominal wall pass through this plane before supplying anterior abdominal wall. Combination of local anaesthetic drugs with adjuvants have been tried in TAP block ${ }^{[6,7]}$. Studies have shown that the use of adjuvant prolongs the effect of local anaesthetic drug \& enhances the duration of analgesia. ${ }^{[8]}$ We decided to use Levobupivacaine as local anaesthetic. Dexamethasone produces anti-inflammatory action as it has a glucocorticoid structure. When added to local anaesthetics as an adjuvant in peripheral blocks, it increases the duration of nerve blockade. ${ }^{[9]}$

In our randomized and double-blind study, we analysed the effects of dexamethasone as adjuvant to levobupivacaine on the duration of analgesia, the time for requirement of rescue analgesia \& analgesia consumption for $24 \mathrm{hrs}$.

\section{MATERIALS AND METHODS}

70 adult parturients belonging to ASA II requiring elective caesarean section via Pfannenstiel incision were recruited in this prospective double-blind study. Patients of $<50 \mathrm{~kg}$ or $>100 \mathrm{~kg}$ weight, with any contraindication to spinal anaesthesia, ASA $>$ II , patients not giving consent for the study were excluded.

The recruited patients were randomly assigned to one of the two groups on the basis of computer-generated random number table, concealed in opaque envelope, which was opened just before caesarean section.

All patients had received intravenous ranitidine $50 \mathrm{mg}$ and metoclopramide $10 \mathrm{mg} 30 \mathrm{~min}$ before transferring to OT. Each patient received spinal anaesthesia with $10-12 \mathrm{mg}$ of $0.5 \%$ heavy bupivacaine at L3-4 level in left lateral position. Bilateral USG-guided TAP block was given to all patients after skin closure. TAP block was administered by the posterior approach using the SonoSite M-turbo ${ }^{\mathrm{TM}}$ Ultrasonography machine. High frequency $(6-13 \mathrm{MHz})$ linear array probe is placed horizontally on abdomen. The three muscle layers in anterolateral part can be traced by scanning from midline towards the area between costal margin \& iliac crest in the midaxillary line. The needle was then pierced anterior to the transducer by in-plane approach. This is referred to as the posterior approach. Drug was injected between internal oblique \& transverse abdominis muscle. The patients either received TAP block with $30 \mathrm{ml} 0.25 \%$ levobupivacaine with $8 \mathrm{mg}$ (2cc) dexamethasone (group $\mathrm{A}$ ) or received $30 \mathrm{ml} 0.25 \%$ levobupivacaine with 2cc saline (group B).

Patients were then transferred to the post anaesthesia care unit. Pain severity was assessed by an investigator blinded to the allotment every $2,4,6,8,12,18$ and $24 \mathrm{~h}$. It was measured using visual analogue score (VAS) $(0=$ no pain and $10=$ worst possible pain). Rescue analgesia was given to patients on demand or when VAS was more than 4 in the form of IV 
tramadol $2 \mathrm{mg} / \mathrm{kg}$. The parameters studied and compared in both the groups were time for first request for analgesia, total tramadol requirement in $24 \mathrm{~h}$ and VAS at $2,4,6,8,12,18,24 \mathrm{~h}$. In PACU, all observations were made by an independent observer who was unaware of group allocation. For sample size calculation, after using 0.05 and 0.2 alpha and beta errors we calculated that 32 patients per group would be required for an experimental study design involving two equal-sized groups. To minimise any effect of data loss, we elected to recruit 35 patients per group into the study. Statistical analysis was done using the SPSS software (SPSS Inc. Released 2009. PASW Statistics for Windows, Version 18.0. Chicago: SPSS Inc.) Demographic data were analysed using Student's $t$-test or Fisher's exact test as appropriate. The comparison of total tramadol requirement, time to first analgesic administration and VAS between the two groups was done by paired $t$-test. Confidence interval was $95 \%$. $\mathrm{P}<0.05$ was considered statistically significant.

\section{RESULTS}

70 patients were recruited in the study, of these 35 were randomised to undergo TAP block with $30 \mathrm{cc} 0.25 \%$ levobupivacaine \& $8 \mathrm{mg}$ dexamethasone and remaining 35 patients with $30 \mathrm{cc} 0.25 \%$ levobupivacaine \& 2cc saline. Demographic profile, pulse, blood pressure and saturation were comparable in both groups. Time for first analgesic administration (tramadol) was prolonged significantly in Group A (mean \pm SD- $12.24 \pm 1.22 \mathrm{hrs}$ ) as compared to Group B (mean \pm SD - 8.37 $\pm 1.07 \mathrm{hrs}), P<0.0001$. Tramadol requirement for $24 \mathrm{hrs}$ in Group A was $115.71 \pm 16.89 \mathrm{mg}$ and for Group B was 198.57 $22.64 \mathrm{mg}$, which was statistically significant $(P<0.0001)$. VAS was noted at $2,4,6,8,12,18$ and $24 \mathrm{~h}$. VAS was greatly reduced in group A for the first 8-10 h post-operatively as compared to patients in group B.

\begin{tabular}{|l|l|l|l|}
\hline & $\begin{array}{l}\text { Group A } \\
\text { Mean } \pm \text { SD }\end{array}$ & $\begin{array}{l}\text { Group B } \\
\text { Mean } \pm \text { SD }\end{array}$ & P value \\
\hline Age & $26.78 \pm 2.78$ & $27.83 \pm 3.15$ & 0.1439 \\
\hline Height & $159.48 \pm 4.55$ & $160.84 \pm 5.68$ & 0.2728 \\
\hline Weight & $74.32 \pm 3.56$ & $73.44 \pm 2.84$ & 0.2570 \\
\hline Duration of surgery & $42.12 \pm 5.60$ & $40.94 \pm 4.26$ & 0.3246 \\
\hline Baseline HR & $76.56 \pm 4.82$ & $74.71 \pm 3.38$ & 0.0673 \\
\hline Baseline SBP & $129.98 \pm 8.17$ & $132.58 \pm 7.22$ & 0.1629 \\
\hline Baseline DBP & $82.54 \pm 2.42$ & $83.80 \pm 3.47$ & 0.0826 \\
\hline Baseline SpO2 & $99.12 \pm 0.8$ & $99.04 \pm 0.6$ & 0.6375 \\
\hline $\begin{array}{l}\text { Time for rescue } \\
\text { andlgesia(hrs) }\end{array}$ & $12.24 \pm 1.22$ & $8.37 \pm 1.07$ & $<0.0001$ \\
\hline $\begin{array}{l}\text { 24hr tramadol } \\
\text { requirement(mg) }\end{array}$ & $115.71 \pm 16.89$ & $198.57 \pm 22.64$ & $<0.0001$ \\
\hline
\end{tabular}

\section{DISCUSSION}

Numerous analgesic regimen have been used for postoperative pain relief. Multimodal analgesia provides excellent results as the combination of various drugs enhances the duration of the block \& even reduces the side effects of individual drugs. ${ }^{[10]}$ Various drugs such as opioids, NSAIDS are being used for providing post-operative analgesia. Respiratory depression, pruritus, sedation, nausea and vomiting are the complications associated with opioids. ${ }^{[11,12]}$ Most extensively used analgesics are the non-steroidal anti-inflammatory drugs but are associated with complications such as bleeding tendencies \& gastrointestinal bleeding. ${ }^{[13]}$ Diclofenac, indomethacin and acetaminophen suppositories have also been used for post-operative pain relief but they counteract predominantly the somatic component of pain. ${ }^{[14]}$ Epidural analgesia has been $\&$ is being used extensively for both intra-operative anaesthesia/ analgesia \& post-operative pain relief, but the engorgement of epidural veins by gravid uterus increases the chances of dural \& vascular puncture \& may even lead to pneumocephalus. ${ }^{[15]}$ Furthermore, it may not be preferred in case of emergency caesarean section \& one study even suggests that it isn't a gold standard technique for postoperative analgesia. ${ }^{[16]}$ TAP block was introduced by Rafi in 2001. ${ }^{[17]} \mathrm{He}$ described it as block delivering local anaesthetics in the TAP using the anatomical landmarks (iliac crest) by first identifying the lumbar triangle of Petit. In 2007, Hebbard et al. introduced the USG-guided approach for TAP block. ${ }^{[18]}$ We used the USG-guided technique as it gives us real time vision \& hence better success rate. In a study of Holte et al, dexamethasone was used as adjuvant to bupivacaine microcapsules by subcutaneous infiltration to obtain $50 \mathrm{~g}$ in $10 \mathrm{ml}$, and a profound increase in analgesia time was observed. ${ }^{[19]}$ In our study, we found that using dexamethasone as adjuvant to levobupivacaine enhanced the duration of analgesia significantly. A study using USG-guided TAP block with $0.25 \%$ levobupivacaine after caesarean section was associated with reduction in total morphine use in $24 \mathrm{~h}$ in the active group (median $18 \mathrm{mg}$ ) compared with the placebo group (median $31.5 \mathrm{mg}$ ). ${ }^{[1]}$ VASs also reduced in the active group compared to placebo group $(96 \mathrm{~mm}$ vs $77 \mathrm{~mm} P=$ 0.008 ). In our study we found duration of analgesia to be more \& tramadol consumption was less in patients receiving dexamethasone as adjuvant. Two similar studies of TAP block were conducted in patients undergoing elective caesarean section under spinal anaesthesia using $20 \mathrm{ml}$ of $0.25 \%$ bupivacaine or levobupivacaine. The studies revealed that pain scores were lower and time of demand for first analgesia was significantly longer in study groups compared to control (no drug) groups. ${ }^{[20,21]}$. In a study by Mishriky et al, the requirement of opioids decreased within the 12 hours after the block $^{[22]}$ TAP block has poor vascularity, and hence the absorption of injected drug is slower \& action is prolonged and not associated with any major complications. We have to be cautious about the dosage of local anaesthetic in pregnancy as parturients are prone for local anesthetic systemic toxicity as there is decreased protein binding, increased availability of free drug. Few studies have been conducted upon dosage of levobupivacaine in TAP block in pregnancy \& its pharmacokinetics. They suggest a dosage of $2 \mathrm{mg} / \mathrm{kg}$ with epinephrine \& $1.5 \mathrm{mg} / \mathrm{kg}$ without epinephrine. ${ }^{[23]}$ We used $0.25 \%$ levobupivacaine $30 \mathrm{ml}(75 \mathrm{mg})$ and also took care not to exceed the toxic dose that is, $1.5 \mathrm{mg} / \mathrm{kg}$.

\section{CONCLUSIONS}

An adjuvant like dexamethasone with local anaesthetic $0.25 \%$ levobupivacaine (bilateral- total $30 \mathrm{~mL}$ ) in ultrasound-guided bilateral TAP block enhances the duration of analgesia \& decreases the postoperative opioid consumption in postcaesarean section patients.

\section{REFERENCES}

1. Leung AY. Postoperative pain management in obstetric anesthesia - New challenges and solutions. J Clin Anesth. 2004;16:57-65.

2. KehletH.surgical stress: the role of pain and analgesia. Br JAnaesth1989;63: 189-95.

3. McDonnell NJ, Keating ML, Muchatuta NA, Pavy TJ, Paech MJ. Analgesia after caesarean delivery. Anqesth Intensive Care 2009;37:539-51.

4. Ismail S. Multimodal analgesia for cesarean section: Evolving role of transversus abdominis plane block. J Obstet Anaesth Crit Care 2012;2:67-8.

5. McDonnell JG, O'Donnell B, Curley G, Heffernan A, Power C, Laffey JG. The analgesic efficacy of transversus abdominis plane block after abdominal surgery: A prospective randomized controlled trial. Anesth Analg. 2007;104:193-7.

6. Abdallah FW, Halpern SH, Margarido CB. Transversus abdominis plane block for postoperative analgesia after Caesarean delivery performed under spinal anaesthesia? A systematic review and meta-analysis. Br J Anaesth 2012; 109: 679-687.

7. Bollag L, Richebe P, Siaulys M, Ortner CM, Gofeld M, Landau R. Effect of transversus abdominis plane block with and without clonidine on postcesarean delivery wound hyperalgesia and pain. Reg Anesth Pain Med 2012; 37: 508-514.

8. Yaksh TL, Ilfeld BM, Wiese AJ. Perineural local anesthetic and adjuvant action: the meaning of an ex vivo data set for efficacy and safety. Reg Anesth Pain Med 2012; 37: 366-368.

9. Rasmussen SB, Saied NN, Bowens C, JR., Mercaldo ND, Schildcrout JS, Malchow RJ. Duration of upper and lower extremity peripheral nerve blockade is prolonged with dexamethasone when added to ropivacaine: a retrospective database analysis. Pain Med (Malden, Mass) 2013; 14:1239-1247.

10. Adeniji AO, Atanda OO. Randomized comparison of effectiveness of unimodal opioid analgesia with multimodal analgesia in post-cesarean section pain management. J Pain Res 2013;6:419-24.

11. Belavy D, Cowlishaw PJ, Howes M, Phillips F. Ultrasound-guided transversus 
abdominis plane block for analgesia after Caesarean delivery. Br J Anaesth. $2009 ; 103: 726-30$

12. Tan TT, Teoh WH, Woo DC, Ocampo CE, Shah MK, Sia AT. A randomised trial of the analgesic efficacy of ultrasound-guided transversus abdominis plane block after caesarean delivery under general anesthesia. Eur J Anaesthesiol. 2012;29:88-94

13. Surakarn J, Tannirandorn Y. Intramuscular diclofenac for analgesia after cesarean delivery: A randomized controlled trial. J Med Assoc Thai 2009:92:733-7

14. Akhavanakbari G, Entezariasl M, Isazadehfar K, Kahnamoyiagdam F. The effects of indomethacin, diclofenac, and acetaminophen suppository on pain and opioids consumption after cesarean section. Perspect Clin Res 2013;4:136-41.

15. Kuczkowski KM. Postduralpuncture headache, intracranial air \& obstetric anaesthesia. Anaesthetist. 2003 Sep;52(9):798-800

16. Rawal N. Epidural technique for postoperative pain: gold standard no more? Reg Anesth Pain Med 2012; 37: 310-317.

17. Rafi AN. Abdominal field block: A new approach via the lumbar triangle. Anesthesia. 2001:56:1024-6.

18. Hebbard P, Fujiwara Y, Shibata Y, Royse C. Ultrasound-guided transversus abdominis plane (TAP) block. Anaesth Intensive Care 2007;35:616-7.

19. Holte K, Werner MU, Lacouture PG, Kehlet H. Dexamethasone prolongs local analgesia after subcutaneous infiltration of bupivacaine microcapsules in human volunteers. Anesthesiol 2002:96: 1331-1335.

20. Srivastava U, Verma S, Singh TK, Gupta A, Saxsena A, Jagar KD, et al. Efficacy of trans abdominis plane block for post cesarean delivery analgesia: A double-blind, randomized trial. Saudi J Anaesth 2015;9:298-302.

21. Cansiz KH, Yedekci AE, Sen H, Ozkan S, Dagli G. The effect of ultrasound guided transversus abdominis plane block for cesarean delivery on postoperative analgesic consumption. Gulhane Med J 2015;57:121-4.

22. Mishriky BM, George RB, Habib AS. Transversus abdominis plane block for analgesia after Cesarean delivery: a systematic review and meta-analysis. Can J Ancesth 2012; 59: 766-778.

23. Miranda P Corvetto MA Altermatt FR, Araneda A Echevarria GC, Cortinez Ll. Levobupivacaine absorption pharmacokinetics with \& without epinephrine during TAP block: analysis of doses based on associated risk of local anaesthetic toxicity. Eur J Clin Pharmacol. 2016 Oct; 72(10):1221-1227. 